\title{
Carbon dioxide sensors for food packaging
}

Isabel M. Perez de Vargas-Sansalvador ${ }^{\mathrm{a}, \mathrm{c}, *}$, Miguel M. Erenas ${ }^{\mathrm{a}, \mathrm{c}}$, Antonio Martínez-Olmos ${ }^{\mathrm{b}, \mathrm{c}}$, Maria Dolores Fernández-Ramos ${ }^{\mathrm{a}, \mathrm{c}}$ and Luis Fermin Capitán-Vallvey ${ }^{\mathrm{a}, \mathrm{c}}$

${ }^{a}$ ECsens, Department of Analytical Chemistry, University of Granada, Granada, 18071, Spain.

${ }^{\mathrm{b}}$ ECsens, CITIC-UGR, Department of Electronics and Computer Technology, University of Granada, Granada, 18071, Spain.

c Unit of Excellence in Chemistry applied to Biomedicine and the Environment of the University of Granada.

"e-mail: isabelpdv@ugr.es

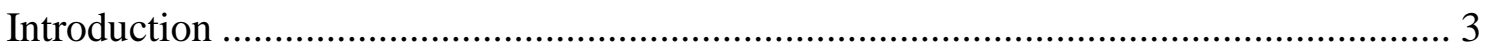

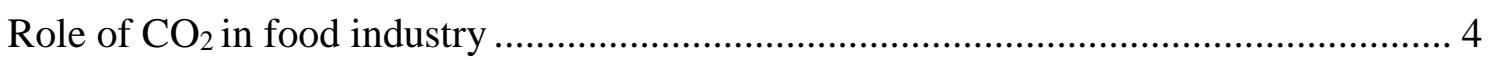

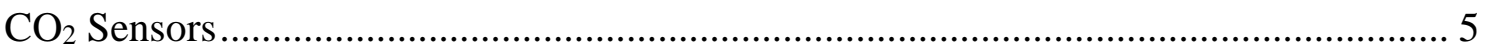

Integration of $\mathrm{CO}_{2}$ sensors in packaged food ......................................................... 8

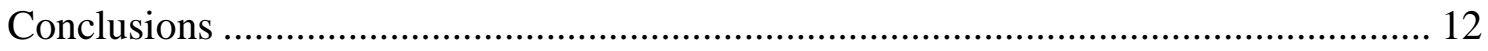

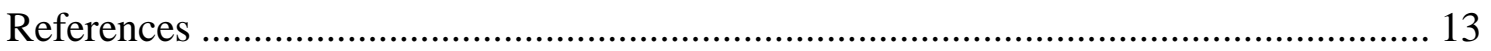

\begin{abstract}
Traditional food packaging objective is the isolation of products from the outer atmosphere to extend their shelf life. In response to current necessities, traditional food packaging has led to smart packaging.

$\mathrm{CO}_{2}$ inside food packages is a key factor to control. $\mathrm{CO}_{2}$ sensors can give information about the modified atmosphere integrity, indicating that the inner atmosphere is intact or if it has been broken and therefore the used by date must not be trusted, or about how fresh is the packaged product.

This article briefly describes the types of packaging (traditional and smart) and how $\mathrm{CO}_{2}$ sensors can be used in the food industry. Different approaches for their integration in packaged food are described and the characteristics that must comply in order to be integrated in the agro-alimentary industry.
\end{abstract}


Keywords: $\mathrm{CO}_{2}$ sensors; Carbon dioxide; Sensors; Food packaging; Intelligent packaging; Agrofood industry; MAP; Freshness sensors; Optical sensors; RFID; NFC; Smartphone; Colorimetry; Luminescence; Bacterial growth. 


\section{Introduction}

Nowadays, the most usual way to find food is packaged. The mission of the package is to isolate products from the outer atmosphere to extend their shelf life, although it fulfils more functions such as: protection, communication, convenience, and containment [1]. Traditional packaging has helped to improve the food industry, although in today's fast paced world, where the industry devoted to food is one of the most important and largest around the world, there is a competition to gain the market. One of the strategies carried out to succeed in the competition is to improve their products in terms of keeping the safety of the produce, the use of environmentally friendly materials or the implementation of new technologies [2].

In response to the new necessities, traditional food packaging has led to smart packaging. Smart packaging accomplishes the four main functions of traditional packaging but it goes further, this means that is capable of giving information about the product or is able to extend their shelf life. Smart packaging covers two kinds of packaging: intelligent packaging and active packaging [3].

Active packaging is defined as packaging where different elements have been integrated on purpose to enhance the system operation [4], this includes keeping or extending the product shelf life. Some examples can be components that absorb ethylene, carbon dioxide, or moisture, as well as oxygen scavengers, or ethanol emitters [5].

Intelligent packaging is a term related to packaging that contains external or internal indicators able to give information about the continent and content, such as history of the package and/or the quality of food packaged [4]. Therefore many examples can be found, it can be a sensor informing about ripeness grade of fruit [6], temperature history [7] or quality of food [8]. Intelligent packaging encompasses packages that are able to sense some properties of the food enclosed or the inner environment, besides this information has to be accessible from the manufacturer to the consumer.

Inside intelligent packaging research, one of the growing areas is the development of $\mathrm{CO}_{2}$ sensors. According to Puligundla et al. "The development of efficient $\mathrm{CO}_{2}$ sensors that can intelligently monitor the gas concentration changes inside a food package and specific to food packaging applications is essential [9]”. Therefore, $\mathrm{CO}_{2}$ sensors capable of being integrated into food packages as freshness indicators that ensure the quality of food are being studied in depth due to the current society's demand for new forms of packaging with improved functions [10]. 
Implemented $\mathrm{CO}_{2}$ sensors in food trays can give information about the state of the food being packaged (spoiled or fresh) as this gas is released because of bacterial respiration. Moreover, determination of $\mathrm{CO}_{2}$ can be used as control of MAP integrity [11]. Commercially $\mathrm{CO}_{2}$ sensors are not found yet in food packaging because manufacturing costs / implementation and physical size of the sensors inhibit their market value [12].

\section{Role of $\mathrm{CO}_{2}$ in food industry}

The main gases used in the food industry are $\mathrm{CO}_{2}$ and $\mathrm{O}_{2}$ in addition to $\mathrm{N}_{2}$. They are used in the preparation of modified atmospheres inside food packages. $\mathrm{CO}_{2}$ is the main antimicrobial factor in MAP [13]. Each fresh food has its own optimal gas composition that needs to be studied for the correct design of the optimal packaging conditions [14].

The concentration of $\mathrm{CO}_{2}$ inside food packages is a key factor to control, mainly for two reasons (Figure 1):

1. MAP integrity: Normally, high concentrations of $\mathrm{CO}_{2}$ are used in MAP or at least concentrations higher than the atmospheric $\mathrm{CO}_{2}$. If the concentration of $\mathrm{CO}_{2}$ is monitored and thus, decreases over time this means that the modified atmosphere has been broken and therefore the shelf by date cannot be trusted.

The control of the integrity of packages is carried out by means invasive methods (the biotest, the electrolytic test, the dye penetration test or the bubble test) that are long and arduous. Some samples randomly selected of each lot are analysed and therefore compromised. If the results show the integrity of the package is not well, all the packages from that batch are disposed without knowing the actual state of them producing an elevated waste. This is not the best way to do it as not the whole lot is studied and can result in compromised packages not analysed [15]. Automatic non-destructive methods, such as $\mathrm{CO}_{2}$ sensors would be the best way to do it, this way would allow reducing food waste and the whole inspection to be performed on line [16].

2. Freshness indication: Fresh products consume the $\mathrm{O}_{2}$ present in the headspace of the package and the $\mathrm{CO}_{2}$ concentration increases overtime due to bacterial active breath. Therefore, the inner atmosphere of fresh food packages constantly changes due to metabolic processes. Increases in the concentration of $\mathrm{CO}_{2}$ overtime are 
expected in packaged fresh food $[17,18]$. This concentration can be correlated with the state of food, and thus bacterial counts has been correlated with the concentration of this gas for chicken [19] and pork meat [20].

Changes in the $\mathrm{CO}_{2}$ concentration overtime inside food packages depend on different factors such as size of the package, packaged produce, packaging material, temperature, moisture, quantity of product, etc. Therefore, all these variables should be taken into account when preparing a $\mathrm{CO}_{2}$ sensor for intelligent packaging applications [21].

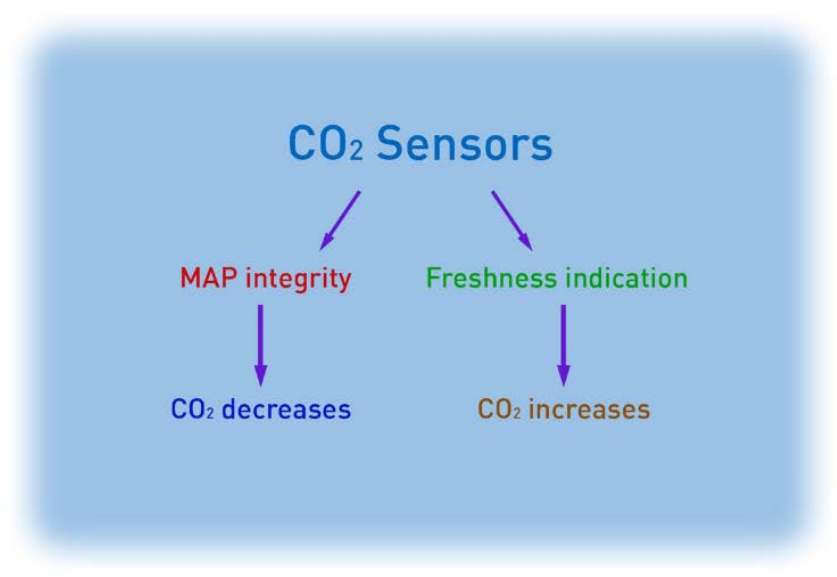

Figure 1. $\mathrm{CO}_{2}$ sensor applications in packaged food

\section{$\mathrm{CO}_{2}$ Sensors}

The IUPAC defines a chemical sensor as a device that transforms chemical information, ranging from the concentration of a specific sample component to total composition analysis, into an analytically useful signal. The chemical information, mentioned above, may originate from a chemical reaction of the analyte or from a physical property of the system investigated [22].

Chemical sensors are composed of various elements that can be combined in three main parts: a receptor part, where there is an interaction with the analyte, a transducer part able to convert the chemical signal into an electrical signal that contains useful analytical information and the amplification and signal processing which permits getting the results in the required units. 
The conventional techniques used to analyse $\mathrm{CO}_{2}$ are gas chromatography [23], infrared spectroscopy and Severinghaus type electrode [24]. These techniques are invasive and hence, totally or partially destructive being not desirable for implementation in the food industry. The main disadvantages of these techniques are among others: high price, requirement of sampling and technical manipulation and large size.

IR spectroscopy has been highly employed for $\mathrm{CO}_{2}$ detection because this gas presents an absorption band around 4.2-4.4 $\mu \mathrm{m}$, therefore the concentration of $\mathrm{CO}_{2}$ can be measured. in the IR region. The drawback is that other substances absorb at the same region, especially water vapour. High humidity is expected inside packaged food and therefore this technique is not useful for applications in the food sector.

Consequently, researchers are doing great efforts to improve $\mathrm{CO}_{2}$ analysis by the use of sensors simplifying the whole process, fabricating cheap, fast, sensitive, in situ, user friendly and miniaturised $\mathrm{CO}_{2}$ sensors [25].

In general, $\mathrm{CO}_{2}$ sensors are classified into electrochemical, mainly amperometric and potentiometric, and optical sensors depending on the operating principle of the transducer [26] .

Electrochemical sensors are not found in food applications because they would be difficult to implement in food packages and would require the breaking of the package. Only a few examples can be found [24, 27] therefore we would focus on optical sensors for $\mathrm{CO}_{2}$.

Optical $\mathrm{CO}_{2}$ sensors are based typically on the acidic properties of this gas. Gaseous $\mathrm{CO}_{2}$ dissolves in water (Figure 2) modifying the $\mathrm{pH}$ that can be highlighted with acid-base indicators or using substances, which solubility depends on the $\mathrm{pH}$. 


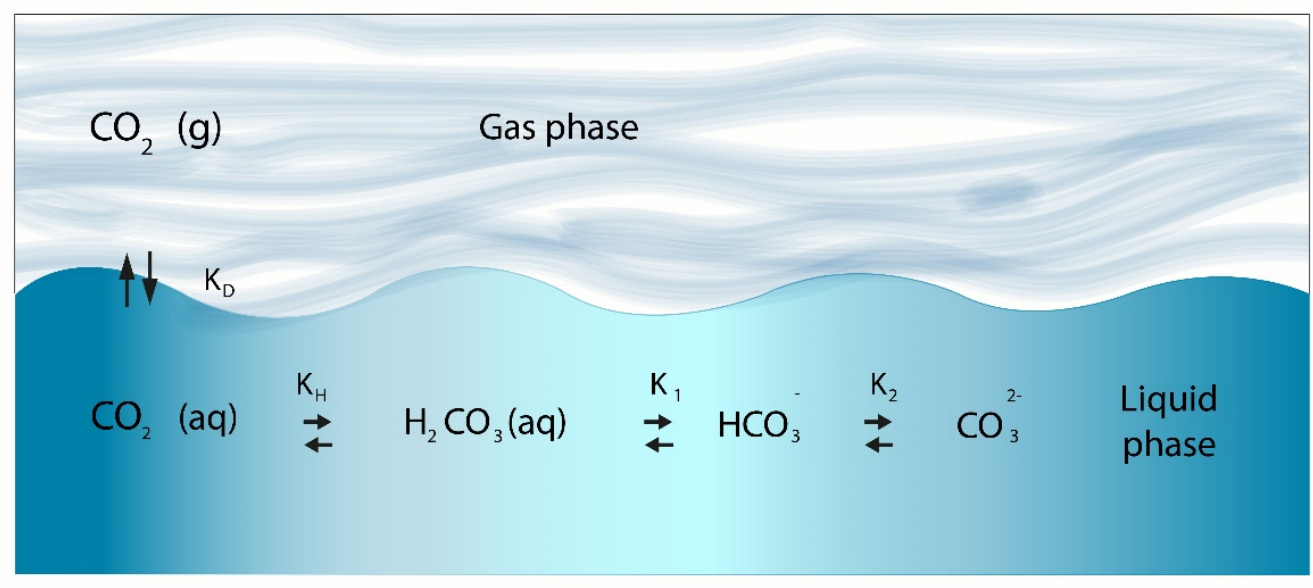

Figure 2. Equilibrium of $\mathrm{CO}_{2}$ in water.

Different $\mathrm{pH}$ indicators have been used to detect $\mathrm{CO}_{2}$ such as meta cresol purple, thymol blue, $\alpha$-naphtholphthalein, or bromothymol blue [28-30]. The pKa of the optimal indicator to detect $\mathrm{CO}_{2}$ must be ca. 6.8. Common colorimetric $\mathrm{CO}_{2}$ optical sensors are solvent based (THF, toluene among others), and contain a phase transfer agent, a lipophilic dye and a base. The drawback of these solvent based sensors are their poor stability under ambient conditions thus to increase the lifetime, especial storage conditions like high humidity, vacuum or/and darkness are always needed [31, 32]. Improvement on stability have been achieved using water based sensors, obtaining stability that makes their use in food applications possible [33].

Generally, these sensors are prepared by forming a membrane deposited on an inert support such as Mylar or other polymeric materials. Other examples can be found with the membranes directly deposited over other surfaces i.e. LED [34], digital color detector [35] or plastic fiber [36].

Based on this acidic properties, luminescence can be measured instead of absorbance or color by means the quenching of the signal of a luminescent substance inert to $\mathrm{CO}_{2}$, whose emission spectrum overlaps with the absorbance spectra of one of the forms of the colorimetric $\mathrm{pH}$ indicator by resonance energy transfer (FRET) [37-39] that implies changes in the lifetime of the emission or by inner-filter effects [40, 41].

The luminescent substances that have been mainly used are porphyrins [42, 43] but other examples can be found such as upconverting nanoparticles [44] and ruthenium complexes [45]. 
The pH-sensitive fluorescent reagent 8-hydroxypyrene-1,3,6-trisulfonic acid (HPTS) has been highly employed in the preparation of $\mathrm{CO}_{2}$ optical sensors [46-48]. Its absorption and emission bands differ between the protonated and the deprotonated form. The protonated form the HPTS shows the excitation and emission peaks at 396 and $430 \mathrm{~nm}$ and the deprotonated form exhibits the excitation and emission peaks at 460 and $515 \mathrm{~nm}$, respectively. Therefore, when the concentration of $\mathrm{CO}_{2}$ increases, a decrease in the green fluorescence is observed [49].

Another strategy for $\mathrm{CO}_{2}$ sensing is based on the formation of carbamic acid derivatives. Neutral organic bases that contain $\mathrm{N}-\mathrm{H}$ bonds can lead to the formation of carbamic acid and carbamate salts in addition to hydrogencarbonate when exposed to $\mathrm{CO}_{2}$ according to the equation 2 [50]. This causes a variation on the $\mathrm{pH}$, which can be highlighted by a $\mathrm{pH}$ dye.

$$
\mathrm{R}_{2} \mathrm{NH}+\mathrm{CO}_{2} \quad \stackrel{+\mathrm{CO}_{2}}{\stackrel{\mathrm{CO}_{2}}{\hookrightarrow}} R_{2} \mathrm{NCOOH}
$$

It is also reported that substituted amidines reacts with $\mathrm{CO}_{2}$ via acid-base reaction changing the hydrophilicity of the compound [51], being able to highlight the presence of $\mathrm{CO}_{2}$ using a solvatochromic dye such as Nile red [52].

\section{Integration of $\mathrm{CO}_{2}$ sensors in packaged food}

Several requirements must be met for the design of $\mathrm{CO}_{2}$ sensors to be applied in the food industry, such as being non-toxic [25]. They must comply the Commission regulation (EC) 450/2009 [53] on active and intelligent materials and articles intended to come into contact with food. Moreover, apart of the toxicity grade of the components of the sensor, the detection system is also highly important. It must be simple, reliable and must leave the package undamaged. Several ways, that have been described in literature, can be applied. For example the use of the naked eye, in which the sensor can alert of changes in the packaged food by means of color changes; in this case a color chart must be also provided as color depends on receptor and illumination conditions [54]. Consumer electronic digital devices such as conventional cameras or Smartphone cameras can be used to detect changes in the color of the sensor, providing more accurate measurements than the use of color charts. The advantage of using Smartphones is the possibility of the use of apps, allowing the detection any moment, anywhere needed [55]. Radio frequency identification (RFID) technology allows the transmission of data using a RFID reader. 
The $\mathrm{CO}_{2}$ sensor can be included in a tag inside the packaged food. The disadvantage of this system is the necessity of an RFID reader [56], therefore it could offer a good solution for companies but not for consumers. There is a new research area that combines alternative sources of energy harvesting with RFID technology, avoiding the use of RFID readers. It is described a passive tag for $\mathrm{O}_{2}$ and $\mathrm{CO}_{2}$ determination based on optical chemical sensors powered by means of two miniaturized solar cells [35]. In that regard and also with the use of smartphones, near-field communication (NFC) can be utilised. NFC is a set of low speed and low range communication protocols that is included in the latest smartphones. It is used for example for contactless payment. Thanks to NFC technology, Smartphones can be used to power and exchange information using a radiofrequency signal between the NFC device and an NFC passive tag [57], this technology is very attractive for future applications.

Next, the most recent $\mathrm{CO}_{2}$ sensors applied to food packaging found in literature are described.

Color- based $\mathrm{CO}_{2}$ sensors:

A mixture of lysine, $\varepsilon$-polylysine and anthocyanins was investigated as colorimetric indicator of $\mathrm{CO}_{2}$ capable to respond to small variations of gaseous $\mathrm{CO}_{2}$ (up to 2.5\%) and to detect direct and reverse transitions. This sensor lasted for various weeks in refrigerated conditions. Evaluations of color was carried out by the naked eye varying from azure to intense purple when the concentration of $\mathrm{CO}_{2}$ increased. The mechanism was based on the formation of the carbamic acid for the reaction of the lysine with $\mathrm{CO}_{2}$ and as $\mathrm{pH}$ indicator anthocyanin was used that is a natural compound extracted from red cabbage, which makes the sensor very attractive for its food grade condition [58]. $\varepsilon$-polylysine was used as antimicrobial agent and to provide color stability. This sensor was applied in poultry samples and showed good correlation with microbial growth patterns, however no reference method was used to validate the results of the sensor.

A chitosan-based $\mathrm{CO}_{2}$ indicator was developed, based on the solubilisation of chitosan molecules in $\mathrm{CO}_{2}$-induced acidic conditions in aqueous medium. Chitosan solubility depends on the $\mathrm{pH}$ conditions, forming a transparent suspension under acidic conditions but opaque under neutral or alkaline conditions. Depending on the quantity of $\mathrm{CO}_{2}$, the dissolution of $\mathrm{CO}_{2}$ varied and therefore the transparency of the mixture. The compound 2-amino-2-methyl-1-propanol was used to take advantage of the formation of the 
carbamic acid, getting a more acidic solution when increasing the concentration of $\mathrm{CO}_{2}$ [59], this sensor was employed packed in LDPE (low density polyethylene) film sachets and inserted in packages of kimchi to check the fermentation process. These packages were stored for two weeks observing a change in the transparency of the sachets from $30 \%$ to $100 \%$ [60]. The liquid phase of the sensor is not the most desirable way to have a sensor for the food industry, because of the possibility of leakage and contamination of food.

A chemical barcode was designed using a mixture of different $\mathrm{pH}$ indicators, obtaining the best results with bromothymol blue and methyl red. The sensor was based on the acidic properties of $\mathrm{CO}_{2}$. It was applied in the detection of spoilage of breast chicken, correlating the quantity of $\mathrm{CO}_{2}$ with the numbers of bacteria present overtime at different temperatures. The sensor demonstrated to be stable for sufficient time to be used commercially. Color changes were measured by a portable Chroma meter [19]. The drawback of this sensor was the transduction system sensor, meaning that for example a color chart should be given in order to get a sensor that could be used by any consumer.

A water based ink was described by Mills et al. [33] containing m-cresol purple, sodium hydrogencarbonate, hydroxyethyl cellulose and glycerol, the sensitivity encountered was less than the solvent based sensors, but the stability was increased. Moreover, it was shown the possibility of being applied to a variety of different surfaces, using a simple applicator, which was an enormous advantage for food applications. A water based colorimetric sensor was prepared using metacresol purple as $\mathrm{pH}$ indicator. In this study the concentration of $\mathrm{CO}_{2}$ released over time was studied in correlation with bacteria counts for total viable counts, Pseudomonads and Enterobateriaceae. The sensor was studied under different conditions of light, humidity and temperature, concluding that was able to be stable for sufficient time given the intended application. The detection was made by the use of a conventional camera analysing the $\mathrm{H}$ parameter of the sensor from the HSV color space [20]. This sensor was then integrated in meat packages showing the ability to detect spoilage before people showed rejection and being stable for the whole period of study. Moreover, an android app was created, therefore spoilage could be detected just using a smartphone [61].

Luminescent-based sensors: 
An optical sensor for $\mathrm{CO}_{2}$ based on FRET was reported [12]. The phosphorescent dye was a Pt-porphyrin and the colorimetric $\mathrm{pH}$ indicator $\alpha$-naphtholphthalein. Thin films were prepared depositing $2 \mu \mathrm{L}$ on an inert support. The sensor showed responses to $\mathrm{CO}_{2}$ in the whole range $\left(0-100 \% \mathrm{CO}_{2}\right)$ with an acceptable speed (response time $1 \mathrm{~min}$ and recovery time $4 \mathrm{~min}$ ). The sensors were exposed to ready-to-eat mixed salad leaves at $4^{\circ} \mathrm{C}$. During storage gas composition inside the packs was also controlled with a reference method (Checkmate $9900 \mathrm{O}_{2} / \mathrm{CO}_{2}$ gas analyser). At certain time intervals the sensors were extracted from the packs and tested with conventional instrumentation, this system lacked of a non-destructive way to measure the concentration of $\mathrm{CO}_{2}$, as the sensor had to be taken out from the package to be measured, on the other hand they were stable under standard packaging conditions which made them promising for the food industry investigating the appropriate way for a non-destructive transduction.

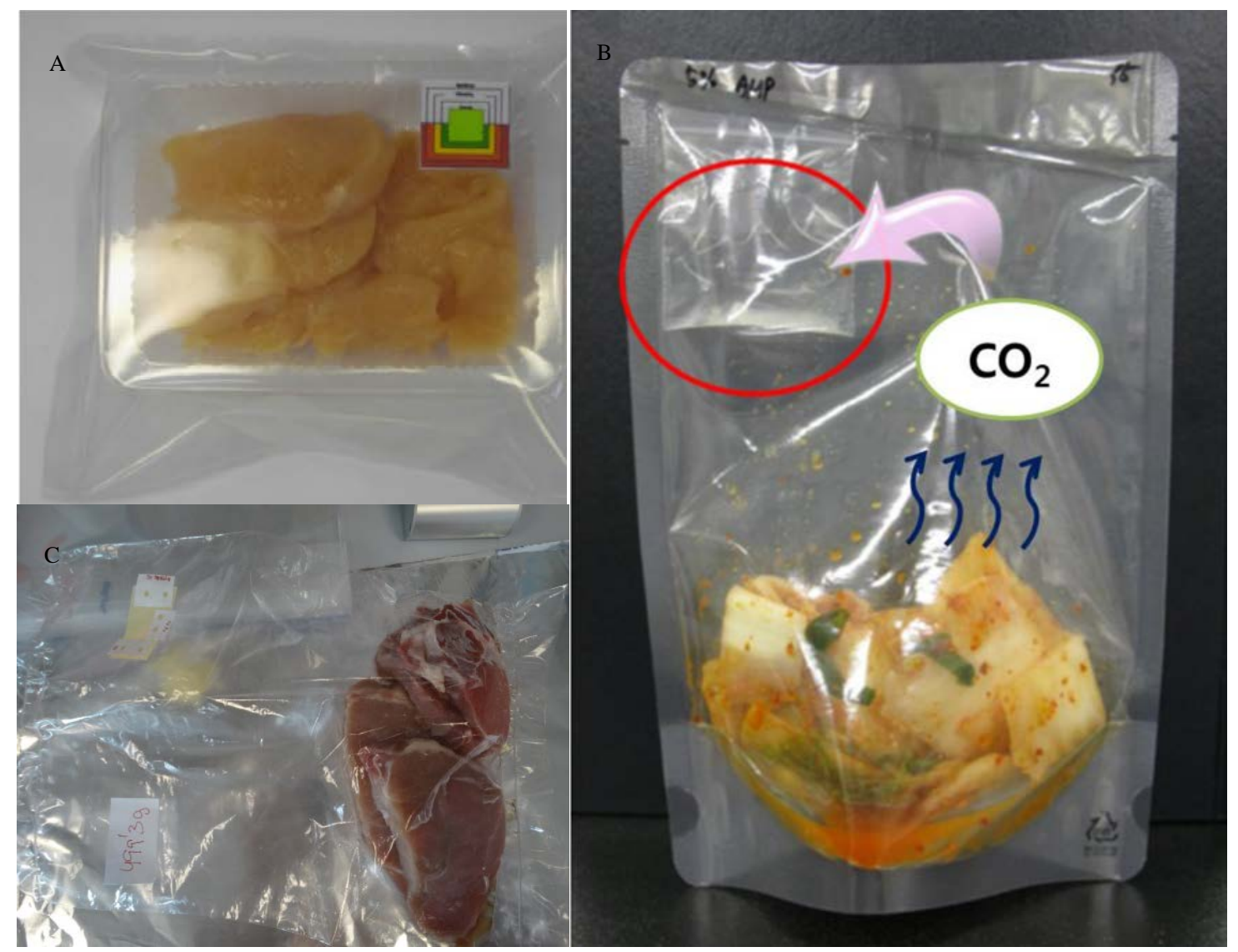

Figure 3. Examples of $\mathrm{CO}_{2}$ sensors integrated in packaged food. A) Barcode for chicken fillets spoilage detection b) CO sensors for pork meat freshness detection and C) Chitosan based $\mathrm{CO}_{2}$ sensor for kimchi fermentation. Figure adapted from A) [19] B) [61] C) [60] 


\section{Conclusions}

Developments in sensor technology are getting closer to commercially viable sensors for food packaging applications, although their utilisation is very limited, each day we are one step closer to find these kinds of sensors in supply chains and supermarkets. To be implemented in the food industry, $\mathrm{CO}_{2}$ sensors must fulfil a list of requirements: simplicity, easy implementation, very low price, reliability, robustness and food grade.

There are several reasons for the absence of commercially $\mathrm{CO}_{2}$ sensors, such as: cost of production and implementation, resistance of companies to new practices, and a way to easily access to the information; but the most important reason is that the ideal $\mathrm{CO}_{2}$ sensor for food applications has not been created yet.

\section{Acknowledgements}

Thanks to the European Union's Horizon 2020 research and innovation programme under grant agreement $\mathrm{N}^{\mathrm{o}} 706303$ (Multisens) 


\section{References}

1. Yam, K.L., P.T. Takhistov, and J. Miltz, Intelligent Packaging: Concepts and Applications. Journal of Food Science, 2005. 70(1): p. R1-R10.

2. Rodríguez-Rojas, A., et al., ¿ $¿$ What is the new about food packaging material? A bibliometric review during 1996-2016. Trends in Food Science \& Technology, 2019. 85 p. 252-261.

3. Lloyd, K., M. Mirosa, and J. Birch, Active and Intelligent Packaging, in Encyclopedia of Food Chemistry, L. Melton, F. Shahidi, and P. Varelis, Editors. 2019, Academic Press: Oxford. p. 177-182.

4. Robertson, G.L., Food Packaging Principles and Practice, 3rd Edition. Editor: edited by, CRC Press Taylor \& Francis Group, Boca Rotan, FL 33487-2742. Journal of Food Processing and Preservation, ed. G.L. Robertson. 2012, Boca Raton: CRC Press, Taylor \& Francis Group. 675.

5. Day, B.P.F., Active packaging of food, in Smart packaging technologies for fast moving consumer goods, J.K.a.P. Butler, Editor. 2008, Wiley. p. 1-17.

6. Kuswandi, B., et al., Real time on-package freshness indicator for guavas packaging. Journal of Food Measurement and Characterization, 2013. 7(1): p. 29-39.

7. Mills, A., et al., Novel time-temperature and 'consume-within' indicator based on gasdiffusion. Chemical Communications, 2016. 52(97): p. 13987-13990.

8. Shukla, V., G. Kandeepan, and M.R. Vishnuraj, Development of on package indicator sensor for real-time monitoring of meat quality. Veterinary World, 2015. 8(3): p. 393397.

9. Puligundla, P., J. Jung, and S. Ko, Carbon dioxide sensors for intelligent food packaging applications. Food Control, 2012. 25(1): p. 328-333.

10. Müller, P. and M. Schmid, Intelligent Packaging in the Food Sector: A Brief Overview. Foods, 2019. 8(1): p. 16.

11. Fang, Z., et al., Active and intelligent packaging in meat industry. Trends in Food Science \& Technology, 2017. 61: p. 60-71.

12. Borchert, N.B., J.P. Kerry, and D.B. Papkovsky, A CO2 sensor based on Pt-porphyrin dye and FRET scheme for food packaging applications. Sensors and Actuators B: Chemical, 2013. 176(0): p. 157-165.

13. Phillips, C.A., Review: Modified Atmosphere Packaging and its effects on the microbiological quality and safety of produce. International Journal of Food Science \& Technology, 1996. 31(6): p. 463-479.

14. Tofteskov, J., et al., Modelling headspace dynamics in modified atmosphere packaged meat. Journal of Food Engineering, 2019. 248: p. 46-52.

15. Smolander, M., E. Hurme, and R. Ahvenainen, Leak indicators for modified-atmosphere packages. Trends in Food Science \& Technology, 1997. 8(4): p. 101-106.

16. Harper, C.L., et al., Developments in food packaging integrity testing. Trends in Food Science \& Technology, 1995. 6(10): p. 336-340.

17. Mattila, T. and R. Ahvenainen, Preincubation time and the use of oxygen indicators in determining the microbiological quality of aseptically packed pea and tomato soup. International Journal of Food Microbiology, 1989. 9(3): p. 205-214.

18. Hong, S.-I. and W.-S. Park, Use of color indicators as an active packaging system for evaluating kimchi fermentation. Journal of Food Engineering, 2000. 46(1): p. 67-72.

19. Rukchon, C., et al., Development of a food spoilage indicator for monitoring freshness of skinless chicken breast. Talanta, 2014. 130(0): p. 547-554.

20. Perez de Vargas-Sansalvador, I.M., et al., Water based-ionic liquid carbon dioxide sensor for applications in the food industry. Sensors and Actuators B: Chemical, 2017. 253: p. 302-309. 
21. Joseph Kerry, P.B., Smart Packaging Technologies for Fast Moving Consumer Goods, ed. P.B. Joseph Kerry 2008: Wiley.

22. Hulanicki, A., S. Glab, and F. Ingman, Chemical sensors: definitions and classification, in Pure and Applied Chemistry. 1991. p. 1247.

23. Mohr, S.A., E.A. Zottola, and G.A. Reineccius, The Use of Gas Chromatography to Measure Carbon Dioxide Production by Dairy Starter Cultures1. Journal of Dairy Science, 1993. 76(11): p. 3350-3353.

24. Neethirajan, S., et al., Development of carbon dioxide (CO2) sensor for grain quality monitoring. Biosystems Engineering, 2010. 106(4): p. 395-404.

25. Ghaani, M., et al., An overview of the intelligent packaging technologies in the food sector. Trends in Food Science \& Technology, 2016. 51: p. 1-11.

26. Zhou, X., et al., Recent Progress on the Development of Chemosensors for Gases. Chemical Reviews, 2015. 115(15): p. 7944-8000.

27. Bibi, F., et al., Wheat gluten, a bio-polymer to monitor carbon dioxide in food packaging: Electric and dielectric characterization. Sensors and Actuators B: Chemical, 2017. 250: p. 76-84.

28. Amao, Y., T. Komori, and H. Nishide, Rapid responsible optical CO2 sensor of the combination of colorimetric change of $\alpha$-naphtholphthalein in poly(trimethylsiliylpropyne) layer and internal reference fluorescent porphyrin in polystyrene layer. Reactive and Functional Polymers, 2005. 63(1): p. 35-41.

29. Chang, Q., et al., Steam-Sterilizable, Fluorescence Lifetime-Based Sensing Film for Dissolved Carbon Dioxide. Biotechnology Progress, 1998. 14(2): p. 326-331.

30. Borisov, S.M., et al., Optical Carbon Dioxide Sensors Based on Silicone-Encapsulated Room-Temperature lonic Liquids. Chemistry of Materials, 2007. 19(25): p. 6187-6194.

31. Fernández-Ramos, M.D., et al., lonic liquids on optical sensors for gaseous carbon dioxide. Analytical and Bioanalytical Chemistry, 2018. 410(23): p. 5931-5939.

32. Aguayo-López, M.L., L.F. Capitán-Vallvey, and M.D. Fernández-Ramos, Optical sensor for carbon dioxide gas determination, characterization and improvements. Talanta, 2014. 126: p. 196-201.

33. Skinner, A.M.a.G.A., Water-based colourimetric optical indicators for the detection of carbon dioxide. Analyst, 2010. 135: p. 1912 - 1917.

34. Pérez de Vargas-Sansalvador, I.M., et al., A new light emitting diode-light emitting diode portable carbon dioxide gas sensor based on an interchangeable membrane system for industrial applications. Analytica Chimica Acta, 2011. 699(2): p. 216-222.

35. Escobedo, P., et al., Flexible passive tag based on light energy harvesting for gas threshold determination in sealed environments. Sensors and Actuators B: Chemical, 2016. 236: p. 226-232.

36. Wysokiński, K., et al., Study on the Sensing Coating of the Optical Fibre $\mathrm{CO}_{2}$ Sensor. Sensors (Basel, Switzerland), 2015. 15(12): p. 31888-31903.

37. Ge, X., Y. Kostov, and G. Rao, High-stability non-invasive autoclavable naked optical CO2 sensor. Biosensors and Bioelectronics, 2003. 18(7): p. 857-865.

38. Neurauter, G., I. Klimant, and O.S. Wolfbeis, Microsecond lifetime-based optical carbon dioxide sensor using luminescence resonance energy transfer. Analytica Chimica Acta, 1999. 382(1): p. 67-75.

39. von Bültzingslöwen, C., et al., Lifetime-based optical sensor for high-level pCO2 detection employing fluorescence resonance energy transfer. Analytica Chimica Acta, 2003. 480(2): p. 275-283.

40. Pérez de Vargas-Sansalvador, I.M., et al., Phosphorescent sensing of carbon dioxide based on secondary inner-filter quenching. Analytica Chimica Acta, 2009. 655(1-2): p. 66-74. 
41. Carvajal, M.A., et al., Hand-held optical instrument for $\mathrm{CO} 2$ in gas phase based on sensing film coating optoelectronic elements. Sensors and Actuators B: Chemical, 2010. 144(1): p. 232-238.

42. Amao, Y. and N. Nakamura, An optical sensor with the combination of colorimetric change of $\alpha$-naphtholphthalein and internal reference luminescent dye for $\mathrm{CO} 2$ in water. Sensors and Actuators B: Chemical, 2005. 107(2): p. 861-865.

43. Perez de Vargas-Sansalvador, I.M., et al., Compact optical instrument for simultaneous determination of oxygen and carbon dioxide. Microchimica Acta, 2011. 172(3-4): p. 455-464.

44. Ali, R., et al., Upconverting nanoparticle based optical sensor for carbon dioxide. Sensors and Actuators B: Chemical, 2010. 150(1): p. 126-131.

45. Marazuela, M.D., M.C. Moreno-Bondi, and G. Orellana, Luminescence Lifetime Quenching of a Ruthenium(II) Polypyridyl Dye for Optical Sensing of Carbon Dioxide. Applied Spectroscopy, 1998. 52(10): p. 1314-1320.

46. Wang, J., et al., Optical carbon dioxide sensor based on fluorescent capillary array. Results in Physics, 2017. 7: p. 323-326.

47. Oter, O., K. Ertekin, and S. Derinkuyu, Ratiometric sensing of $\mathrm{CO} 2$ in ionic liquid modified ethyl cellulose matrix. Talanta, 2008. 76(3): p. 557-563.

48. Mills, A. and D. Yusufu, Highly $\mathrm{CO} 2$ sensitive extruded fluorescent plastic indicator film based on HPTS. Analyst, 2016. 141(3): p. 999-1008.

49. Chu, C.-S. and Y.-L. Lo, Fiber-optic carbon dioxide sensor based on fluorinated xerogels doped with HPTS. Sensors and Actuators B: Chemical, 2008. 129(1): p. 120-125.

50. Alshamrani, A.K., J.R. Vanderveen, and P.G. Jessop, $A$ guide to the selection of switchable functional groups for CO2-switchable compounds. Physical Chemistry Chemical Physics, 2016. 18(28): p. 19276-19288.

51. Jessop, P.G., et al., A solvent having switchable hydrophilicity. Green Chemistry, 2010. 12(5): p. 809-814.

52. Ali, R., et al., Optical Sensing Scheme for Carbon Dioxide Using a Solvatochromic Probe. Analytical Chemistry, 2011. 83(8): p. 2846-2851.

53. COMMISSION REGULATION (EC) No 450/2009, in COMMISSION REGULATION (EC) No 450/2009 of 29 May 2009 on active and intelligent materials and articles intended to come into contact with food, E. Union, Editor. 2009, Official Journal of the European Union

54. Ripesense. Available from: http://www.ripesense.co.nz/.

55. López-Ruiz, N., et al., Determination of 02 using colour sensing from image processing with mobile devices. Sensors and Actuators B: Chemical, 2012. 171-172(0): p. 938-945.

56. Ramos, A., et al., Nitrogen Dioxide Wireless Sensor Based on Carbon Nanotubes and UWB RFID Technology. IEEE Antennas and Wireless Propagation Letters, 2015. 14: p. 1145-1148.

57. Escobedo, P., et al., General-purpose passive wireless point-of-care platform based on smartphone. Biosensors and Bioelectronics, 2019: p. 111360.

58. Saliu, F. and R. Della Pergola, Carbon dioxide colorimetric indicators for food packaging application: Applicability of anthocyanin and poly-lysine mixtures. Sensors and Actuators B: Chemical, 2018. 258: p. 1117-1124.

59. Jung, J., P. Puligundla, and S. Ko, Proof-of-concept study of chitosan-based carbon dioxide indicator for food packaging applications. Food Chemistry, 2012. 135(4): p. 2170-2174.

60. Jung, J., et al., Chitosan-based carbon dioxide indicator to communicate the onset of kimchi ripening. LWT - Food Science and Technology, 2013. 54(1): p. 101-106.

61. Isabel M. Perez de Vargas-Sansalvador, M.M.E., Antonio Martínez-Olmos, Fatima Mirza-Montoro, Dermot Diamond and Luis Fermin Capitan-Vallvey, Smartphone based meat freshness detection. Food Chemistry_ Under revision, 2019. 
